\title{
An Assessment of the Acceptability of COVID-19 Vaccine in Uganda: An Online-Based Cross-Sectional Study
}

Patrick Albert Ipola ${ }^{2,3,4 *}$, Steven Kakooza ${ }^{1}$, Gabriel Tumwine ${ }^{2}$, Lawrence Nduhukyire ${ }^{4}$, Claire Nnannyanzi ${ }^{4}$, Dan Muramuzi ${ }^{4}$, Joa Tusabe $^{4,5}$, Michael Muhoozi ${ }^{4,5}$, Benson Ngolobe ${ }^{3,6}$ and Joseph Kagaayi ${ }^{4}$

${ }^{1}$ Central Diagnostic Laboratory, Kampala Uganda

${ }^{2}$ Uganda Research Training Collaborative (URTC) Kampala, Uganda

${ }^{3}$ Makerere University, College of Veterinary Medicine Animal Resources and Biosecurity Kampala, Uganda

${ }^{4}$ Makerere University School of Public Health, Uganda

${ }^{5}$ Makerere University Center Health and Population Research, Uganda

${ }^{6}$ Makerere University-Johns Hopkins University Research Collaboration, Uganda

${ }^{7}$ Inferenix Data Analytics and Research Services, Uganda

*Corresponding author: Ipola Patrick Albert, Uganda Research Training Collaborative (URTC) Kampala, Uganda; Email: patrickalbert4@outlook.com

Received: June 21, 2021; Accepted: July 01, 2021; Published: July 28, 2021

\begin{abstract}
Background: Globally, health systems are optimistic about Coronavirus (COVID-19) vaccine introduction as one of the solutions for containment and elimination of the COVID-19 virus. However, the success of the vaccination efforts depends on the number of people who get vaccinated to reach herd immunity. Our study assessed the acceptability of the COVID-19 vaccine among Ugandans and the determinants for acceptability when the vaccine is made available.

Methods: Between October 6, 2020, and November 6, 2020, an anonymous web-based cross-sectional survey was conducted among Ugandans who could access an online semi-structured questionnaire designed using Google forms. The Google form was shared on email and social network platforms including Facebook, Twitter, Instagram, and WhatsApp. Participants that completed the survey received information encouraging them to spread the survey link to all their contacts.

Results: Overall acceptability of the COVID-19 vaccine was 396 of 604 (66\%). Acceptability of COVID-19 vaccine was associated with having a Doctor of Philosophy (Ph.D.): APR: 2.90; 95\% CI [1.33-6.45]. On the other hand, acceptability of COVID-19 vaccine was negatively associated with female sex: APR: 0.75; 95\% CI [0.66-0.85], history of Adverse Events Following Immunization: APR: 0.63; 95\% CI [0.42-0.96], not believing that COVID-19 is real: APR: 0.63; 95\% CI [0.47-0.84] and not believing that COVID-19 has a vaccine; APR: 0.86; 95\% CI [0.76-0.98].
\end{abstract}

Conclusions: Most participants indicated an intention to accept to receive the COVID-19 vaccine. However, addressing social demographic differences and health education is needed to increase the intention to receive the COVID-19 vaccine when available.

Keywords: Acceptability of COVID-19 Vaccine; COVID-19 vaccination; Health Belief Model; COVID-19 in Uganda

\section{Introduction}

The World Health Organization (WHO) declared the Corona Virus Disease 2019 (COVID-19) as a Public Health Emergency of International Concern (PHEIC) on 31th of January 2020, and finally a pandemic on 11th March 2020 [1]. As of September 23, 2020, there were 1,175,271 confirmed cases and 25,825 confirmed death due to COVID-19 in Africa [2]. The COVID-19 pandemic has had a huge impact across societies, with governments worldwide imposing restrictions of movement and other measures such as mandatory use of face coverings or quarantine to prevent the spread of the virus.

Most governments have pinned the hope of returning to normality on the availability of a COVID-19 vaccine [3]. As of November
6, Vaccine trials had reported encouraging results indicating that a COVID-19 vaccine is safe and produces a good immune response $[4,5]$. Despite being recognized as one of the most successful public health measures, vaccination is perceived as unsafe and unnecessary by a growing number of parents. Anti-vaccination movements have been implicated in lowered vaccine acceptance rates and the increase in vaccine-preventable disease outbreaks and epidemics [6]. The vast spread of COVID-19 misinformation could hinder the public acceptance of the COVID-19 vaccine [7].

Low-income countries like Uganda may not be able to afford to purchase vaccines for all its population. The COVAX plan is unlikely to be enough and Africa will have to be proactive in securing vaccines 
[8]. However, the success of a vaccination program will depend on the availability of vaccines for the vaccination program and the rates of uptake among the population. It is important to assess the public acceptance of the COVID-19 vaccine, factors for intention to accept or reject the vaccine, and willingness to pay for the vaccine among Ugandans to prepare and develop effective policies and messaging for vaccination now, to maximize uptake when a vaccine becomes available for Ugandans. In this study, we assessed, the acceptability of the COVID-19 vaccine among Ugandans, the determinants, barriers, and facilitators of acceptability of the COVID-19 vaccine.

\section{Methods}

\section{Study Participants and Survey Design}

Between October 6, 2020, and November 6, 2020, an anonymous web-based cross-sectional survey was conducted in Uganda. The researchers used a semi-structured questionnaire designed using Google forms. This helped generate a link that was shared on email and social network platforms like Facebook, Twitter, Instagram, and WhatsApp. Using online social media networks was appropriate during this period because of the COVID-19 lockdown and movement restrictions in Uganda. The survey targeted potential respondents of up to 1,000 and 641 were reached. Of these, 604 respondents completed all survey questions and provided written informed consent online. Only participants that were Ugandan residents who had internet access and aged above 18 years were included in the study. Participants that completed the survey received information encouraging them to spread the survey link to all their contacts. The questionnaire was pretested to a similar population and similar observations of the pretested population were eliminated from data analysis.

\section{Instruments}

A semi-structured and self-reported survey questionnaire was used to solicit data from participants. This contained informed consent, socio-demographic background, trust issues relating to COVID-19, information source, COVID-19 Beliefs, and COVID-19 vaccine acceptability.

\section{Socio-demographic Measures}

Information on sex, residence, marital status, religion, job category, education, and employment status were collected.

\section{COVID-19 Beliefs}

The Health Belief Model constructs were used to measure the Beliefs and attitudes $[9,10]$. Each construct of the model was measured using two questions assessed on a five-level Likert scale; Perceived Susceptibility (you have high chances of getting COVID-19 and the nature of your work puts you at a higher risk of getting COVID-19); Perceived Severity (you can get incapacitated if you contracted COVID-19 and you can die if you contracted COVID-19) Perceived Benefit (vaccination with safe COVID-19 vaccine will safeguard you from COVID-19 and Life will get normal if people get vaccinated) Perceived Barriers ( getting COVID-19 vaccine may put you in danger and vaccines are safe for human use); and Cues to Action ( discovery of COVID-19 vaccine makes you want to get it and trust of Information from $\mathrm{MoH}$ ).

\section{Acceptability of COVID-19 Vaccine}

The outcome variable of this study was acceptability for the COVID-19 vaccine. It was measured using the question "Will you accept to receive the COVID-19 vaccine if it becomes available for use?" Acceptability of the COVID-19 vaccine was then computed as the proportion of people who self-reported having accepted the vaccine out of the total number of respondents.

\section{Statistical Analysis}

Data cleaning and analysis were performed using Microsoft Excel 2013 and STATA SE version 14 respectively. The results were described using measures of central tendency, dispersion, and associations. For continuous variables, like age, mean (and the standard deviation) was presented, for all categorical variables, frequencies, and percentages were presented. The outcome variable of this study was acceptability for the COVID-19 vaccine; which was computed as the proportion of people who self-reported to accept the vaccine if available out of the total number of respondents. Binary modified Poisson regression analysis was performed with a $95 \%$ confidence interval to determine significant associations between categorical dependent and independent variables.

\section{Ethical Considerations}

The study was conducted in adherence to the Institutional Research Ethics and the newly set guideline that adhere to UNCST COVID-19 Standard Operating Procedures. Personnel Identifiers of the respondents were not collected and there was no invasive procedure done on the participants. Formal ethical approval was granted by the Multidisciplinary Laboratory Technology Society Research, Science and Technology Committee, (Ref MLTS/RSTS/02/20). An online consent form documented the aims, nature, and procedure of the study. Anonymity and confidentially were strictly maintained. Respondents who didn't consent to participate in the study were not able to access the rest of the questionnaire. While the respondents who consented to participate in the study were able to access the questionnaire and fill it out.

\section{Results}

The median (IQR) age of the study participants was 29 (25-33) years; with the majority aged 25-34 years. More so, more than half of the participants were male; 384 (63.6\%), not married; 352 (58.3\%), employed; 400 (66.2\%) and resided in the central region; 348 (57.6\%). About half of the participants had attained undergraduate education; 280 (46.4\%) (Table 1).

The majority of the participants had ever been vaccinated; 500(82.8\%), had no history of Adverse Event Following Immunization (AEFI); 512 (84.8\%); and more than half did not have a friend with a history of AEFI; 400 (66.2\%). Majority of the participants perceived COVID-19 to be real; 520 (86.1\%). About half believed that COVID-19 neither had a vaccine nor treatment; 288 (47.7\%) and 288 (47.7\%) respectively. More than half reported to observe COVID-19 ministry of health guidelines; 344 (57.3\%) (Table 2). 
Patrick Albert Ipola (2021) An Assessment of the Acceptability of COVID-19 Vaccine in Uganda: An Online-Based Cross-Sectional Study

Table 1: Socio-demographic characteristics.

\begin{tabular}{|l|c|}
\hline Characteristics & Frequencies (\%) \\
$\mathrm{n}=604$ \\
\hline Age & \\
Median (IQR): 29 (25-33) years & $138(22.9)$ \\
$20-24$ years & $200(33.1)$ \\
$25-29$ years & $145(24.0)$ \\
$30-34$ years & $58(9.6)$ \\
$35-39$ years & $26(4.3)$ \\
$40-45$ years & $37(6.1)$ \\
$\geq 45$ years & \\
\hline Sex & $384(63.6)$ \\
Male & $220(36.4)$ \\
Female & \\
\hline Marital status & $252(41.7)$ \\
Married & $352(58.3)$ \\
Not married & \\
\hline Region of residence & $348(57.6)$ \\
Central & $68(11.3)$ \\
Eastern & $52(8.6)$ \\
Northern & $136(22.5)$ \\
Western & \\
\hline Education level & $20(3.3)$ \\
Secondary education & $16(2.6)$ \\
Diploma education & $280(46.4)$ \\
Undergraduate education & $276(45.7)$ \\
Postgraduate education & $12(2.0)$ \\
Ph.D. Education & \\
\hline Religion & $220(36.4)$ \\
Anglican & $184(30.5)$ \\
Catholic & $132(21.9)$ \\
Pentecostal/born again & $40(6.6)$ \\
Moslems & $28(4.6)$ \\
Other religions & \\
\hline Employment status & \\
Employed & $(25.8)$ \\
Not employed & \\
Student & \\
\hline
\end{tabular}

A higher percentage of participants trusted all the information sources except for social media and friends and families. A majority (83\%) trusted information from international health organizations; followed by $79 \%$ who trusted information from the health care providers (Figure 1).

Table 2: Knowledge and perceptions about COVID-19 vaccination.

\begin{tabular}{|l|c|}
\hline Characteristics & $\mathrm{n}(\%)$ \\
\hline Ever been vaccinated & $500(82.8)$ \\
Yes & $76(12.6)$ \\
No & $28(4.6)$ \\
Not sure & \\
\hline History of AEFI & $36(6.0)$ \\
Yes & $512(84.8)$ \\
No & $56(9.2)$ \\
Not sure & \\
\hline Known friend with AEFI & $204(33.8)$ \\
Yes & $400(66.2)$ \\
No & \\
\hline The perception that COVID-19 is real & $520(86.1)$ \\
COVID is real & $40(6.6)$ \\
COVID is not real & $44(7.3)$ \\
Not sure & \\
\hline COVID-19 has treatment & $124(20.5)$ \\
Yes & $288(47.7)$ \\
No & $192(31.8)$ \\
Not sure & \\
\hline COVID-19 has a vaccine & $120(19.9)$ \\
Yes & $288(47.7)$ \\
No & $196(32.5)$ \\
Not sure & \\
\hline Observing Ministry of health guidelines & $344(57.3)$ \\
Yes & $8(1.3)$ \\
No & \\
Sometimes & \\
& \\
\hline
\end{tabular}

Trust in International health Organizations

Trust in friends and family

Trust in social media
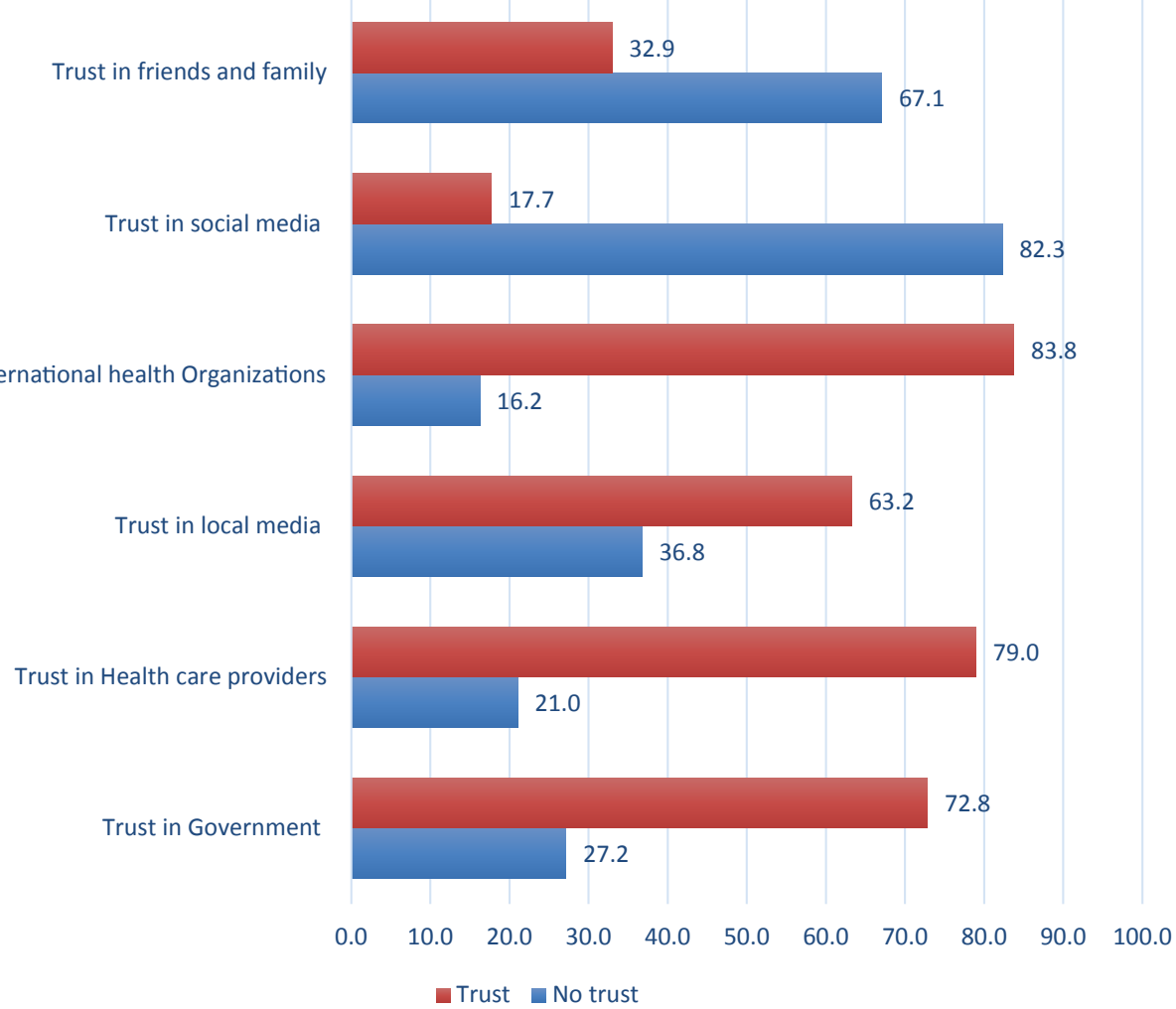

Figure 1: Percentage of participants with trust in COVID-19 information sources. 
Perceived Susceptibility
You have high chances of getting Covid-19

Your work puts you at higher risk of Covid-19

Perceived Severity

You can get incapacitated if you contracted Covid-19

You can die if you contracted Covid-19

Perceived Benefit

Vaccination will safeguard you from Covid-19

Life will get normal if people get vaccinated

Perceived Threats

Getting Covid-19 vaccine may put you in danger Vaccines are safe for Human use

Clues to Action

Discovery of Covid-19 vaccine makes you want to get it Trust of Covid-19 Information from $\mathrm{MoH}$
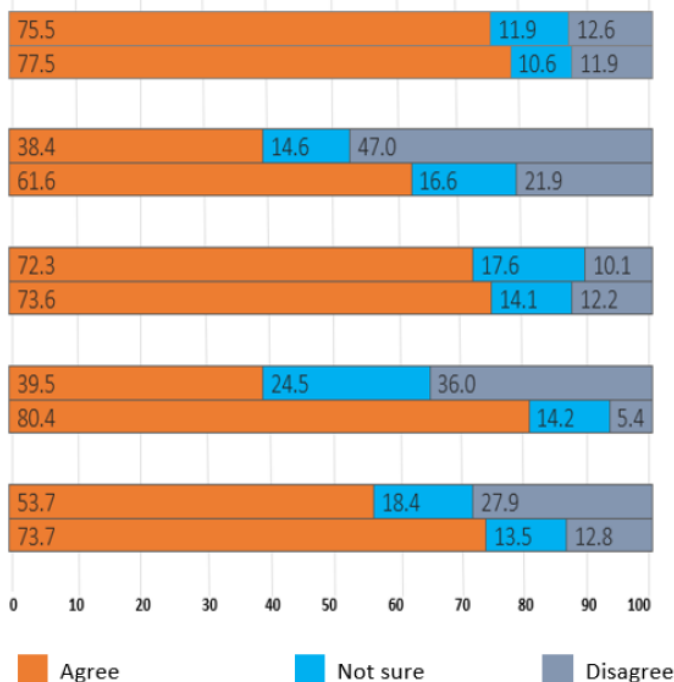

Figure 2: Percentage of Participants' agreement with the Health Belief Model constructs.

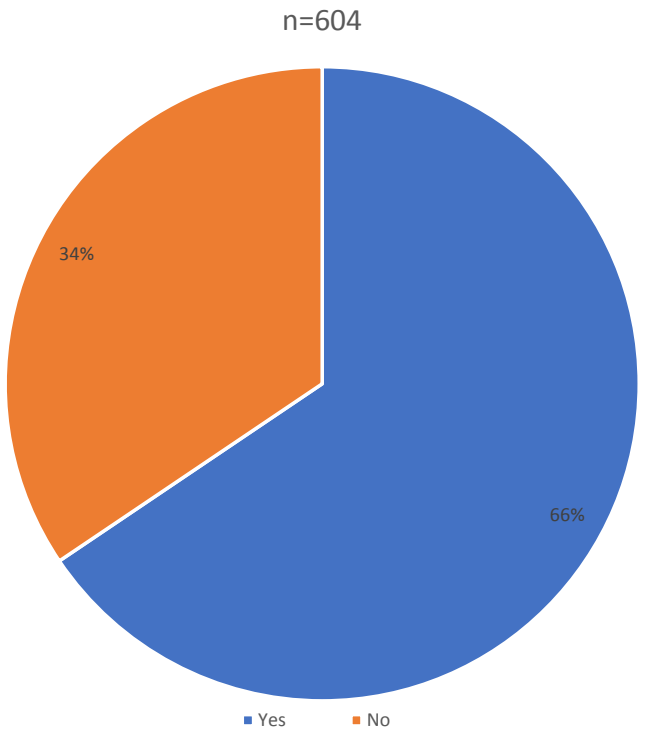

Figure 3: Percentage of Covid-19 Vaccine Acceptability among participants.

A higher percentage of participants perceived they were susceptible to COVID-19 [high chances of getting COVID-19 (75.5\%) and work nature puts you at higher risk of getting COVID-19 (77.5\%)]. A higher percentage also perceived that the COVID-19 vaccine will benefit them [vaccination will safeguard you from COVID-19 (72.3\%) and life will get back to normal if people get vaccinated (73.6\%)]. On the perceived threats construct, $39.5 \%$ of the participants perceived that the COVID-19 vaccine may be a threat to them while $80.4 \%$ perceived vaccines were safe for human use thus not a threat to them (Figure 2).

Out of 604 complete responses, 396 (66\%) of the participants indicated an intention to accept to receive the COVID-19 vaccine when it becomes available for use, and 208 (34\%) indicated an intention not to accept (Figure 3).

At multivariable analysis, the following factors were significantly associated with acceptability of COVID-19 vaccine: sex, education level, religion, history of AEFI, perception about COVID-19 and its vaccine, and trust in information from health care providers and the World Health Organization (WHO). There was a positive statistically significant association between acceptability of COVID-19 vaccine and Doctor of Philosophy (Ph.D.) education. Participants who had attained Ph.D. education were 2.9 times as likely to accept the COVID-19 vaccine compared to participants who had attained secondary education. (APR 2.90, 95\% CI [1.33-6.45]).

On the other hand, there was a negative statistically significant association between acceptability of COVID-19 vaccine and female sex, Catholic and Pentecostal religions, having a history of AEFI, the perception that COVID-19 is not real and has no vaccine, and lack of trust in health care providers and WHO.

Female participants were 25\% less likely to accept the COVID-19 vaccine as compared to male participants, APR: 0.75 ; $95 \%$ CI [0.660.85]. Compared to Anglicans, Catholics and Pentecostals were $18 \%$ and $16 \%$ less likely to accept COVID-19 vaccine, APR: 0.82; 95\% CI [0.73-0.92] and APR: 0.84; 95\% CI [0.73-0.97] respectively. Participants who had a history of AEFI were 0.63 times as likely to accept the COVID-19 vaccine as individuals who did not have a history of AEFI, APR: 0.63; 95\% CI [0.42-0.96]. Participants who didn't believe that COVID-19 is real and those who didn't believe that COVID-19 has a vaccine were $37 \%$ and $14 \%$ less likely to accept COVID-19 vaccine, APR: 0.63 ; 95\% CI [0.47-0.84] and APR: 0.86; 95\% CI [0.76-0.98] respectively. Finally, participants who didn't trust information from health care providers and WHO were 0.75 times and 0.6 times as likely to accept the COVID-19 vaccine as participants who trusted information from health care providers and WHO, APR: 0.75; 95\% CI [0.61-0.92] and APR: 0.60; 95\% CI [0.45-0.79] respectively (Table 3).

\section{Discussion}

The COVID-19 vaccine is considered one of the most outstanding ways to tackle the COVID-19 pandemic. However, the success of the vaccination efforts depends on the number of people who get 
Patrick Albert Ipola (2021) An Assessment of the Acceptability of COVID-19 Vaccine in Uganda: An Online-Based Cross-Sectional Study

Table 3: Bivariate Association for Variables Affecting the Intention to Accept COVID-19 Vaccine.

\begin{tabular}{|c|c|c|c|c|}
\hline \multirow{2}{*}{ Background characteristics } & \multicolumn{2}{|c|}{ Acceptability of vaccine } & \multirow{2}{*}{ Crude PR (95\% CI) } & \multirow{2}{*}{$\begin{array}{l}\text { Adjusted PR } \\
(95 \% \mathrm{CI})\end{array}$} \\
\hline & Yes $n=396$ & No $n=208$ & & \\
\hline $\begin{array}{l}\text { Age } \\
20-24 \text { years } \\
25-29 \text { years } \\
30-34 \text { years } \\
35-39 \text { years } \\
40-45 \text { years } \\
\geq \text { years }\end{array}$ & $\begin{array}{l}102(25.8) \\
119(30.1) \\
94(23.7) \\
44(11.1) \\
16(4.0) \\
21(5.3)\end{array}$ & $\begin{array}{l}36(17.3) \\
81(38.9) \\
51(24.5) \\
14(6.7) \\
10(4.8) \\
16(7.7)\end{array}$ & $\begin{array}{c}\text { Ref. } \\
0.81[0.69-0.94]^{* *} \\
0.88[0.75-1.02] \\
1.03[0.86-1.22] \\
0.83[0.60-1.15] \\
0.77[0.57-1.03]\end{array}$ & \\
\hline $\begin{array}{l}\text { Sex } \\
\text { Male } \\
\text { Female } \\
\end{array}$ & $\begin{array}{l}286(72.2) \\
110(27.8)\end{array}$ & $\begin{array}{c}98(47.1) \\
110(52.9)\end{array}$ & $\begin{array}{c}\text { Ref } \\
0.67[0.58-0.78]^{* * *}\end{array}$ & $\begin{array}{c}\text { Ref } \\
0.75[0.66-0.85]^{* * *}\end{array}$ \\
\hline $\begin{array}{l}\text { Marital status } \\
\text { Married } \\
\text { Not married } \\
\end{array}$ & $\begin{array}{l}172(43.4) \\
224(56.6)\end{array}$ & $\begin{array}{c}80(38.5) \\
128(61.5)\end{array}$ & $\begin{array}{c}\text { Ref } \\
0.93[0.83-1.05]\end{array}$ & \\
\hline $\begin{array}{l}\text { Region of residence } \\
\text { Central } \\
\text { Eastern } \\
\text { Northern } \\
\text { Western }\end{array}$ & $\begin{array}{c}228(57.6) \\
36(9.1) \\
44(11.1) \\
88(22.2)\end{array}$ & $\begin{array}{c}122(57.7) \\
32(15.4) \\
8(3.9) \\
48(23.1)\end{array}$ & $\begin{array}{c}\text { Ref. } \\
0.81[0.64-1.02] \\
1.29[1.12-1.48]^{* * *} \\
0.99[0.85-1.14]\end{array}$ & \\
\hline $\begin{array}{l}\text { Education level } \\
\text { Secondary } \\
\text { Diploma } \\
\text { Undergraduate } \\
\text { Postgraduate } \\
\text { PhD } \\
\end{array}$ & $\begin{array}{c}4(1.0) \\
16(4.0) \\
200(50.5) \\
164(41.4) \\
12(3.0) \\
\end{array}$ & $\begin{array}{c}16(7.7) \\
0(0) \\
80(38.4) \\
112(53.9) \\
0(0) \\
\end{array}$ & $\begin{array}{c}\text { Ref } \\
5.00[2.08-12.02]^{* * *} \\
3.57[1.48-8.61]^{* *} \\
2.97[1.23-7.18]^{*} \\
5.00[2.08-12.02]^{* * *}\end{array}$ & $\begin{array}{c}\text { Ref } \\
2.06[0.94-4.50] \\
1.82[0.84-3.95] \\
1.43[0.66-3.10] \\
2.90[1.31-6.45]^{\star *}\end{array}$ \\
\hline $\begin{array}{l}\text { Religion } \\
\text { Anglican } \\
\text { Catholic } \\
\text { Pentecostal/born again } \\
\text { Moslems } \\
\text { Other religions } \\
\end{array}$ & $\begin{array}{c}168(42.4) \\
112(28.3) \\
68(17.2) \\
28(7.1) \\
20(5.0) \\
\end{array}$ & $\begin{array}{c}52(25.0) \\
72(34.6) \\
64(30.8) \\
12(5.8) \\
8(3.8) \\
\end{array}$ & $\begin{array}{c}\text { Ref } \\
0.80[0.69-0.91]^{* *} \\
0.67[0.56-0.81]^{* * *} \\
0.92[0.74-1.14] \\
0.94[0.73-1.20]\end{array}$ & $\begin{array}{c}\text { Ref } \\
0.82[0.73-0.92]^{\star *} \\
0.84[0.73-0.97]^{*} \\
0.94[0.71-1.24] \\
0.85[0.70-1.03] \\
\end{array}$ \\
\hline \begin{tabular}{|l|} 
Employment status \\
Employed \\
Not employed \\
Student \\
\end{tabular} & $\begin{array}{c}260(65.6) \\
28(7.1) \\
108(27.3)\end{array}$ & $\begin{array}{c}140(67.3) \\
20(9.6) \\
48(23.1)\end{array}$ & $\begin{array}{c}\text { Ref } \\
0.90[0.70-1.15] \\
1.07[0.94-1.21] \\
\end{array}$ & \\
\hline $\begin{array}{l}\text { History of AEFI } \\
\text { No } \\
\text { Yes } \\
\text { Not sure } \\
\end{array}$ & $\begin{array}{c}348(87.9) \\
12(3.0) \\
36(9.1) \\
\end{array}$ & $\begin{array}{c}164(78.9) \\
24(11.5) \\
20(9.6) \\
\end{array}$ & $\begin{array}{c}\text { Ref } \\
0.49[0.31-.0 .78]^{\star *} \\
0.95[0.77-1.16] \\
\end{array}$ & $\begin{array}{c}\text { Ref } \\
0.63[0.42-0.96]^{*} \\
0.97[0.81-1.16] \\
\end{array}$ \\
\hline $\begin{array}{l}\text { COVID-19 is real } \\
\text { Real } \\
\text { Not real } \\
\text { Not sure } \\
\end{array}$ & $\begin{array}{c}372(93.9) \\
20(5.1) \\
4(1.0) \\
\end{array}$ & $\begin{array}{c}148(71.2) \\
20(9.6) \\
40(19.2) \\
\end{array}$ & $\begin{array}{c}\text { Ref } \\
0.70[0.51-0.96]^{*} \\
0.13[0.05-0.32] \\
\end{array}$ & $\begin{array}{c}\text { Ref } \\
0.63[0.47-0.84]^{\star *} \\
0.22[0.09-0.55]^{\star *}\end{array}$ \\
\hline \begin{tabular}{|l|} 
COVID-19 has treatment \\
Has treatment \\
No treatment \\
Not sure \\
\end{tabular} & $\begin{array}{c}68(17.2) \\
196(49.5) \\
132(33.3) \\
\end{array}$ & $\begin{array}{l}56(26.9) \\
92(44.2) \\
60(28.9) \\
\end{array}$ & $\begin{array}{c}\text { Ref } \\
1.24[1.04-1.48]^{*} \\
1.25[1.04-1.51]^{*} \\
\end{array}$ & \\
\hline $\begin{array}{l}\text { COVID-19 has a vaccine } \\
\text { Has vaccine } \\
\text { No vaccine } \\
\text { Not sure } \\
\end{array}$ & $\begin{array}{c}84(21.2) \\
188(47.5) \\
124(31.3) \\
\end{array}$ & $\begin{array}{c}36(17.3) \\
100(48.1) \\
72(34.6) \\
\end{array}$ & $\begin{array}{c}\text { Ref } \\
0.93[0.81-1.08] \\
0.90[0.77-1.06] \\
\end{array}$ & $\begin{array}{c}\text { Ref } \\
0.86[0.76-0.98]^{*} \\
0.92[0.80-1.07] \\
\end{array}$ \\
\hline $\begin{array}{l}\text { Trust in social media } \\
\text { Has trust } \\
\text { No trust } \\
\end{array}$ & $\begin{array}{c}82(20.7) \\
314(79.3) \\
\end{array}$ & $\begin{array}{c}32(15.4) \\
176(84.6) \\
\end{array}$ & $\begin{array}{c}\text { Ref } \\
0.89[0.78-1.02]\end{array}$ & \\
\hline $\begin{array}{l}\text { Trust in HCP } \\
\text { Has trust } \\
\text { No trust } \\
\end{array}$ & $\begin{array}{c}350(88.4) \\
46(11.6)\end{array}$ & $\begin{array}{c}127(61.1) \\
81(38.9) \\
\end{array}$ & $\begin{array}{c}\text { Ref } \\
0.49[0.40-0.63]^{\star * *}\end{array}$ & $\begin{array}{c}\text { Ref } \\
0.75[0.61-0.92]^{\star *} \\
\end{array}$ \\
\hline $\begin{array}{l}\text { Trust in WHO } \\
\text { Has trust } \\
\text { No trust }\end{array}$ & $\begin{array}{c}366(92.4) \\
30(7.6)\end{array}$ & $\begin{array}{c}140(67.3) \\
68(32.7)\end{array}$ & $\begin{array}{c}\text { Ref } \\
0.42[0.31-0.57]^{* * *}\end{array}$ & $\begin{array}{c}\text { Ref } \\
0.60[0.45-0.79]^{* * *}\end{array}$ \\
\hline
\end{tabular}

${ }^{*}<0.05 ;{ }^{* *}<0.01 ;{ }^{* * *}<0.001$ level of significance AEFI-Adverse Events Following Immunization HCP-Health care providers, WHO-World Health Organization. 
vaccinated to reach herd immunity. Thus, it's crucial to know and understand the acceptability of the vaccine and the factors that included an intention to accept the COVID-19 vaccine. Our study assessed the acceptability of the COVID-19 vaccine and the factors that influenced the intention to accept.

This study found the acceptability of the COVID-19 vaccine to be $65.6 \%$. This is comparable to a survey conducted in 19 countries which found $71.5 \%$ of participants reported that they would be very or somewhat likely to take a COVID-19 vaccine [13]; a study in the USA where $69 \%$ of the adults indicated an intention to accept the COVID-19 vaccine; [11] a web-based study in Saudi Arabia that revealed $64.7 \%$ of participants indicated an intention to uptake the COVID-19 vaccine [12]; and a similar study in western Uganda that found $53.6 \%$ intention to accept COVID-19 vaccine. Our findings are one of the first estimates of acceptability of a COVID-19 vaccine in Uganda and can be used together with other similar studies to guide projections of future vaccine uptake and as well understand the reasons for intentions to accept the COVID-19 vaccine.

Participants who had attained Ph.D. education were 2.9 times as likely to accept the COVID-19 vaccine compared to participants who had attained secondary education. This is comparable to a survey conducted in 19 countries which found higher levels of acceptability among participants with higher education [12]. This may be because they have a better understanding and exposure to relevant information regarding the COVID-19 vaccine. During the vaccine roll-out, government and health care providers and community-based social mobilization strategies will need to put more focus to provide more information to people with secondary education and below.

Female participants were 25\% less likely to accept the COVID-19 vaccine as compared to male participants. This is similar to the study done in Congo which found more Male health workers were willing to accept COVID-19 Vaccine compared to females health workers [13]. Studies in the USA have indicated similar findings where men were more likely to accept the COVID-19 vaccine than women $[11,14]$. This could indicate that females may hesitate to receive the COVID-19 vaccine compared to males. Further studies on the general population and key populations may be needed to assess and understand COVID-19 vaccine acceptability [15].

Participants who had a history of AEFI were 0.63 times as likely to accept the COVID-19 vaccine compared to individuals who did not have a history of AEFI. This may be because of fear of suffering from another adverse reaction [16-18].

A higher percentage of participants perceived they were susceptible to COVID-19 and also a high percentage perceived that the COVID-19 vaccine will benefit them. This could explain the $65.6 \%$ acceptability of the COVID-19 vaccine [19-21].

Participants who didn't believe that COVID-19 is real and those who didn't believe that COVID-19 has a vaccine were $37 \%$ and $14 \%$ less likely to accept COVID-19 vaccine. This could be because of their lack of belief that COVID-19 is a serious public health threat to them thus the hesitancy to receive the COVID-19 vaccine.
Our study had some limitations in the design and data collection methods. We used a web-based questionnaire that required internet access and knowledge of how to read. This was because of the movement restrictions and government guidance on social distancing to reduce the spread of the COVID-19 virus. This may have led to selection bias against the individuals who couldn't access the internet and couldn't read the web-based questionnaire as reflected by the majority of the respondents having secondary education and above. However, the inference generated is important in the generation of a picture of the acceptability levels of the COVID-19 vaccine. Evidence from community survey which includes illiterate and nonilliterate class is key to assess sub-group acceptability levels without discriminating in access to web and internet devices.

We asked the participants to report their intention to receive the COVID-19 vaccine if the vaccine became available in the future. This was hypothetical; however, the true intention to take the COVID-19 vaccine may change when the vaccine is made available in Uganda.

We also registered a low response rate of 604 respondents making the findings less generalizable for the entire population in Uganda. Despite the limitations of our findings, our study is among the first studies to be conducted in Uganda and thus will provide a framework from which more studies will be conducted to better understand the acceptability for the COVID-19 vaccine among Ugandans and the determinants for acceptability of COVID-19 vaccine.

\section{Conclusion}

Most participants indicated an intention to accept to receive the COVID-19 vaccine. However, Policy Makers; governments; and Health Care Providers need to address Social demographic differences like sex, level of education, and religion, and their influence in intention to receive the COVID-19 vaccine. Other determinants for intention to receive the COVID-19 vaccine-like history of adverse reactions, knowledge on COVID-19 need to be addressed by right and targeted health education before mass vaccination campaign.

\section{References}

1. Hua J, Shaw R (2020) Coronavirus (Covid-19) 'infodemic' and emerging issues through a data lens: The case of China. Int J Environ Res Public Health. [crossref]

2. H. E. Programme, “COVID-19 COVID-19,” pp. 1-10.

3. Sherman SM, et al. (2020) COVID-19 vaccination intention in the UK: results from the COVID-19 vaccination acceptability study (CoVAccS), a nationally representative cross-sectional survey. Hum Vaccines Immunother [crossref]

4. Dagotto G, Yu J, Barouch DH (2020) Approaches and Challenges in SARS-CoV-2 Vaccine Development. Cell Host Microbe vol. 28, no. 3, pp. 364-370. [crossref]

5. Folegatti PM, et al. (2020) Safety and immunogenicity of the ChAdOx1 nCoV-19 vaccine against SARS-CoV-2: a preliminary report of a phase $1 / 2$, single-blind, randomized controlled trial. Lancet vol. 396, no. 10249, pp. 467-478. [crossref]

6. Dubé E, Vivion M, MacDonald NE (2014) Vaccine hesitancy, vaccine refusal, and the anti-vaccine movement: influence, impact, and implications. Expert Review of Vaccines. [crossref]

7. Pennycook G, McPhetres J, Zhang Y, Lu JG, Rand DG (2020) Fighting COVID-19 Misinformation on Social Media: Experimental Evidence for a Scalable AccuracyNudge Intervention. Psychol Sci vol. 31, no. 7, pp. 770-780. [crossref]

8. Sisay OB, Smith E, Crone DD, Andersen H, Mamo LT, "A Covid-19 Vaccination Plan for Africa." 
9. Coe AB, S. B. S. Gatewood, Moczygemba LR, J.-V. "Kelly" R. Goode (2012) The use of the health belief model to assess predictors of intent to receive the novel (2009) H1N1 influenza vaccine. Inov Pharm vol. 3, no. 2.

10. Costa MF (2020) Health belief model for coronavirus infection risk determinants. Rev Saude Publica vol. 54, pp. 1-11. [crossref]

11. Reiter PL, Pennell ML, Katz ML (2021) Acceptability of a COVID-19 vaccine among adults in the United States: How many people would get vaccinated? Vaccine no. xxxx.

12. Lazarus JV, et al. (2020) A global survey of potential acceptance of a COVID-19 vaccine. Nat Med [crossref]

13. Nzaji MK, Ngombe LK, Mwamba GN, Miema JM, Lungoyo CL, Mwimba BL (2020) Acceptability of Vaccination Against COVID-19 Among Healthcare Workers in the Democratic Republic of the Congo. [crossref]

14. Dustin Gibson, ${ }^{*}$ Ph.D.; Smisha Agarwal1, 1, MBBS MBA Ph.D.; Ankita Meghani, Ph.D.; P. M. M. Rupali J. Limaye, 1, 2 Ph.D., MPH, MA; Alain Labrique (2021) COVID-19 Vaccine Acceptability and Inequity in the United States: Results from a nationally representative survey.

15. Power K, Power K (2020) The COVID-19 pandemic has increased the care burden of women and families and families. Sustain Sci Pract Policy vol. 16, no. 1, pp. 67-73.
16. Al-Wora Y, Ming L, Dhabali A, Al-Shami A (2021) Adverse reactions of COVID-19 vaccine among frontline workers in Fujairah, UAE. pp. 1-6.

17. Mojamamy GM, Albasheer OB, Mahfouz MS (2018) Prevalence, knowledge, attitude, and practices associated with influenza vaccination among healthcare workers in primary care centers in Jazan, Saudi Arabia: A cross-sectional study. Trop J Pharm Res vol. 17, no. 6, pp. 1201-1207.

18. Khattak FA, et al. (2021) Prevalence of Parental refusal rate and its associated factors in routine immunization by using WHO Vaccine Hesitancy tool: A Cross-sectional study at district Bannu, KP, Pakistan. Int J Infect Dis vol. 104, pp. 117-124. [crossref]

19. Kim S, Kim S (2021) Searching for a general model of conspiracy theories and its implication for public health policy: Analysis of the impacts of political, psychological, structural factors on conspiracy beliefs about the covid-19 pandemic. Int J Environ Res Public Health vol. 18, no. 1, pp. 1-28. [crossref]

20. Attema A, L'Haridon O, Raude J, Seror V (2021) Beliefs and Risk Perceptions About COVID-19: Evidence From Two Successive French Representative Surveys During Lockdown. Front Psychol vol. 12, no. February, pp. 1-16. [crossref]

21. Karić T, Međedović J (2021) Covid-19 conspiracy beliefs and containmentrelated behavior: The role of political trust. Pers Individ Dif vol. 175, no. January. [crossref]

\section{Citation:}

Albert Ipola P, Kakooza S, Tumwine G, Nduhukyire L, Nnannyanzi C, et al. (2021) An Assessment of the Acceptability of COVID-19 Vaccine in Uganda: An OnlineBased Cross-Sectional Study. Prev Med Epid Public Heal Volume 2(4): 1-7. 